\title{
AS CANTIGAS DE SANTA MARIA: UMA ANÁLISE SEMIÓTICA
}

\author{
SAINT MARY'S SONG: A SEMIOTIC ANALYSIS
}

\author{
Gislene Silva \\ Universidade Estadual Paulista
}

\begin{abstract}
RESUMO: Este trabalho tem como objetivo realizar uma análise semiótica da Cantiga de Santa Maria intitulada Non deve null'ome, que se trata de uma cantiga de louvor à Virgem Maria, produzida durante o período medieval. Para realizar a análise da cantiga escolhida, utilizamos a teoria semiótica pautada no percurso gerativo da expressão, buscando observar como o sentido é gerado nesse texto a partir dos seus diversos níveis de pertinência - desde os signos até as formas de vida -, além de compreender as relações estabelecidas entre os planos de expressão e de conteúdo. Verificamos que nas Cantigas de Santa Maria ocorre a congruência que define um gênero textual: tanto o tipo textual quanto o tipo discursivo estão em harmonia.
\end{abstract}

PALAVRAS-CHAVE: Análise semiótica; Cantiga de Santa Maria; Percurso gerativo da expressão; Níveis de pertinência.

\begin{abstract}
This paper aims to perform a semiotic analysis of the Saint Mary's Song named Non deve null 'ome, which is a song of praise to the Virgin Mary, produced during the medieval period. In order to perform the analysis, we adopted the semiotic theory based on the generative path of expression. The objective was to observe how the meaning is constructed in this text from its different levels of pertinence - from the signs to the forms of life -, and to understand the relationships established between the plans of expression and the content. We verified that in the Saint Mary's Song there is the congruence that defines a textual genre: the textual type and discourse type are in harmony.
\end{abstract}

KEYWORDS: Semiotic analyses; Saint Mary's Song; Generative path of expression; Levels of pertinence.

\section{INTRODUÇÃO}

Este trabalho tem como objetivo fazer a análise de uma Cantiga de Santa Maria utilizando como base teórica a Semiótica, com foco no percurso gerativo da expressão, nas relações estabelecidas entre os planos de expressão e de conteúdo (semiose) buscando explicitar como o sentido é gerado nos diversos níveis de pertinência, desde os signos até às formas de vida, no texto escolhido para a análise.

As Cantigas de Santa Maria (doravante CSM) são obras, produzidas durante o período medieval na Europa em galego-português, que contêm texto, melodia e pintura. Totalizando 420 cantigas, esses textos são de dois tipos: as cantigas de miragres, que narram os milagres alcançados pela Virgem Maria, tais como a cura de enfermos, socorro a perigos e ajuda às decisões do Rei D. Afonso X; e as cantigas de loores, com caráter 


\section{Revista do SELL}

v. 6 , no. 3

ISSN: $1983-3873$

mais lírico, que louvam a Virgem Maria como auxiliadora, mediadora e interventora (COSTA, 2006, p. 23).

Para a realização da nossa análise, utilizaremos a cantiga intitulada Non deve null' ome ${ }^{1}$, que traz em seu mote inicial a seguinte informação: Esta é de loor a Santa Maria, que mostra/porque razon encarnou nostro sennor en ela. Com essa informação, já sabemos de qual tema trata a cantiga, que é de louvor à Virgem progenitora de Jesus. Tendo em vista as definições semióticas de expressão e de conteúdo, buscamos compreender de que maneira esse conteúdo - o louvor à Virgem Maria por ter sido a responsável por trazer Jesus ao mundo - é expresso através dessa cantiga, ou seja, buscamos entender como esse louvor manifesta-se ao longo dos versos desse texto.

\section{A SEMIÓTICA}

A semiótica é um campo de estudo recente que descende das reflexões saussurianas acerca da necessidade de se estabelecer uma ciência que abarcasse os sistemas de signos não-linguísticos. A semiótica distingue-se de outros estudos linguísticos por propor uma metalinguagem própria com o objetivo de descrever a significação em geral, o que inclui também o sentido veiculado pelas línguas (CORTINA; MARCHEZAN, 2011, p. 395). Assim, para a semiótica, "há uma instância do sentido que goza de um estatuto comum independente de sua manifestação em diferentes linguagens" (CORTINA; MARCHEZAN, 2011, p. 396), ou seja, o sentido pode se manifestar independentemente das textualizações, ou processo de constituição do texto, já que o texto é um plano da expressão de um conteúdo.

O objeto de estudo da semiótica é a significação como resultado das articulações de sentido, de modo que é essa constituição do sentido que a semiótica busca expressar. Além disso, a semiótica também se preocupa em explicitar o modo através do qual o sentido se constitui, assim, busca-se o quê por vias do como. Por fim, a semiótica pode ser definida, então, como uma teoria geral da significação (CORTINA; MARCHEZAN, 2011, p. 394). De acordo com Fiorin (1999, p. 13), a semiótica "é uma teoria gerativa, porque concebe o processo de produção do texto como um percurso gerativo, o que vai do mais simples e abstrato ao mais complexo e concreto, num processo de enriquecimento semântico". Dessa

\footnotetext{
${ }^{1}$ Caso o leitor se interesse em ouvir essa cantiga, ela está disponível sob a forma de vídeo no seguinte link: https://www.youtube.com/watch?v=r8Gtg6JDtA4. Acesso em: 17 de agosto de 2017.
} 


\section{Revista do SELL}

v. 6 , no. 3

ISSN: $1983-3873$

forma, para a semiótica, temos já no processo de produção textual a construção do sentido do texto, pois esse processo proporciona o enriquecimento semântico que se completa com o texto.

Tendo como objeto de estudo a significação, ou seja, o conjunto de relações responsáveis pelo sentido do texto, a semiótica pressupõe que o sentido surge, então, dessas relações e não é algo isolado. Assim, a semiótica não busca propriamente o sentido, mas a sua arquitetura, não busca estudar o conteúdo, mas a forma do conteúdo. Por fim, vale ressaltar que a semiótica busca compreender como o texto diz o que diz (FIORIN, 1999, p. 13).

Outro aspecto importante da semiótica que merece a nossa atenção é o fato de que o seu campo epistemológico pode ser delimitado por quatro "grandezas": expressão, conteúdo, forma e substância (CORTINA; MARCHEZAN, 2011, p. 398). Cortina e Marchezan (2011, p. 398-399) explicam que, para Saussure, a distinção entre forma e substância e a proposição de que a língua é responsável por produzir uma forma, e não uma substância, delimitam o objeto da linguística e definem a sua atuação na fronteira da combinação entre conteúdo e expressão.

O percurso gerativo da expressão, elaborado por Fontanille (2007), apresenta diversos níveis que podem ser analisados separadamente ou em conjunto, sendo esses níveis: signos, textos-enunciados, objetos, cenas práticas, estratégias, formas de vida, cultura. Todos esses níveis são importantes para que possamos entender como um conteúdo é expresso num determinado texto e são indispensáveis para a construção do sentido do texto. Por isso, nas nossas análises, buscaremos entender a maneira como a cantiga selecionada é construída, levando em conta os vários níveis que constituem o percurso gerativo da expressão, desde os signos utilizados na cantiga, até as formas de vida suscitadas por esse texto. Tendo em vista que, de acordo com Portela (2008, p. 107) "a cultura em si é uma unidade dificilmente decomponível e analisável, a não ser pelo exame dos seis níveis de pertinência que ela subsume e sincretiza", não trataremos desse nível de pertinência neste trabalho, limitando-nos a tratar, como último nível, as formas de vida. 


\section{Revista do SELL}

v. 6 , no. 3

ISSN: $1983-3873$

\section{A CONSTRUÇÃO DO SENTIDO EM NON DEVE NULL'OME}

A Cantiga de Santa Maria selecionada para a realização da análise semiótica neste trabalho, intitulada Non deve null' ome, apresenta-nos um mote, que a identifica como uma cantiga de louvor à Virgem, por ter sido a responsável por gerar e dar à luz a Jesus Cristo, Filho de Deus. Além do mote, essa cantiga também é formada por um refrão e seis estrofes. No refrão dessa cantiga, que precede a primeira estrofe, já encontramos a ideia principal, ou seja, a lição que depreenderemos desse relato. Esse refrão, constituído de dois versos, será repetido ao final de cada estrofe que compõe a cantiga, no entanto, como verificamos na primeira estrofe transcrita a seguir, somente o primeiro verso do refrão se repete:

(1) E dultar non deve, por quanto vos direi, porque, se non foss' esto, non viramos Rei que corpos e almas nos julgass', eu o sei, como Jeso-Cristo nos verrá joigar. Non deve null' ome desto per ren dultar...

Todas as seis estrofes dessa cantiga são constituídas de cinco versos, sendo que o último verso de cada estrofe é também o primeiro verso do refrão (Non deve null' ome desto per ren dultar). Passaremos, agora, para a análise dessa cantiga, a partir dos diversos níveis que constituem o percurso gerativo da expressão, buscando compreender como o sentido desse texto se constrói, desde os signos que o compõem até às formas de vida suscitadas por ele.

\subsection{SIGNOS}

O primeiro nível de pertinência do percurso gerativo da expressão é o nível dos signos ou signos-figuras, sendo o nível das unidades mínimas de significação. Vamos considerar então, como signos, os fonemas presentes nessa cantiga, que se unem para formar palavras. $\mathrm{Na}$ análise da cantiga selecionada, esse nível é muito importante, pois os signos são organizados de modo a gerar sonoridade e ritmo, já que uma característica das CSM é o fato de terem sido produzidas para serem reproduzidas musicalmente.

Como podemos observar na estrofe transcrita acima no exemplo (1), os três primeiros versos apresentam o mesmo tipo de rima, já que encontramos dois verbos e um 


\section{Revista do SELL}

v. 6 , no. 3

ISSN: $1983-3873$

substantivo que possuem a mesma terminação [CeI $]^{2}$, além disso, o quarto verso rima com o refrão, já que esses dois versos apresentam dois verbos terminando em [Car]. Esse esquema, como já dissemos anteriormente, se repete ao longo das próximas cinco estrofes, sendo que o quarto verso e o refrão terão sempre a mesma rima [Car]. Os três primeiros versos das próximas estrofes apresentam as seguintes rimas: [Cews], [Ca], [Cer], [Cor], [Cow].

Outra característica da cantiga selecionada é que seus versos são alexandrinos ou dodecassílabos, isto é, são versos compostos de doze sílabas poéticas, contadas até a última sílaba tônica. O uso dos versos alexandrinos é bastante comum na composição de poemas e, fazendo a escanção do primeiro verso da primeira estrofe, temos a seguinte contagem de sílabas poéticas:

$$
\begin{aligned}
& \text { E / dul / tar / non / de / ve/ por / quan / to / vos / di / rei } \\
& \begin{array}{llllllllllll}
1 & 2 & 3 & 4 & 5 & 6 & 7 & 8 & 9 & 10 & 11 & 12
\end{array}
\end{aligned}
$$

Observando a composição silábica e a presença das rimas nos versos, verificamos que o trabalho com os signos sonoros e a sua combinação nas cantigas é fundamental para que seja criada a melodia nesses textos, possibilitando que sejam cantados. Temos aqui, então, um intenso trabalho com o significante e com a forma desse significante, o que contribuirá para a compreensão de todo o texto, pois, por apresentar uma forma regular, esse texto permite a sua execução musical e repetição, possibilitando a sua passagem de um indivíduo ao outro, ampliando o seu alcance social.

\subsection{TEXTO-ENUNCIADO}

Passando agora para a análise do segundo nível de pertinência do percurso gerativo da expressão, buscaremos compreender o texto-enunciado com o qual estamos lidando neste trabalho. Tendo em vista que, de acordo com Portela (2008, p. 102, grifos do autor), "não basta ao sujeito perceber a existência de um fenômeno, a questão, no nível da pertinência dos textos-enunciados, é conferir sentido ao que é percebido, é posicionar-se seja como intérprete seja como produtor em relação ao que é percebido", buscaremos

\footnotetext{
2 Para a representação das rimas presentes nos versos das cantigas, utilizaremos a transcrição fonética, que vem sempre entre colchetes [ ]. Além disso, utilizaremos C para representar a consoante genérica que antecede os fonemas que constituem a rima.
} 


\section{Revista do SELL}

v. 6 , no. 3

ISSN: $1983-3873$

interpretar a cantiga selecionada atuando como intérprete-produtor do sentido produzido por esse texto.

Para entendermos como o sentido se constrói no texto, é importante que consideremos os conceitos de coesão, da ordem textual, e a coerência, da ordem discursiva, duas variáveis regidas e reguladas pela congruência, três dimensões dessa forma de "negociação" que, segundo Fontanille (1999, p. 18), existem entre os tipos textuais e discursivos que resultam em determinado gênero (PORTELA; SCHWARTZMANN, 2012, p. 76, grifos dos autores).

A coesão, da ordem textual, trata da organização das sequências de um texto e dos processos que organizam e hierarquizam os segmentos textuais (PORTELA; SCHWARTZMANN, 2012, p. 76). Considerando que os tipos textuais podem ser classificados em a) longo $x$ breve e b) aberto $x$ fechado, a cantiga se classifica como um texto breve e fechado. A cantiga selecionada pode ser considerada como breve, pois o evento narrado ou a duração da história é breve, já que o louvor à Virgem, por ter sido a responsável por gerar e dar à luz a Jesus, ocorre em apenas seis estrofes. Além disso, essa cantiga também pode ser considerada fechada, pois a unidade de leitura e a unidade de edição são coincidentes, já que as partes desse texto só fazem sentido umas em relação às outras. Dessa forma, não podemos, por exemplo, tentar compreender um único verso isoladamente, mesmo o refrão, que se repete ao longo do texto, faz sentido em relação aos outros versos de cada estrofe, pois é utilizado para retomar e enfatizar o que foi dito anteriormente. Assim, a cantiga em análise está pautada na concentração por apresentar um espaço textual reduzido, que se limita a seis estrofes com cinco versos cada, além dos dois versos do refrão, fornecendo, então, o máximo de significação.

$\mathrm{Na}$ cantiga selecionada, constatamos que a coesão se dá por diversos segmentos, como o paralelismo, visto que todos os versos estão organizados paralelamente devido à sua simetria, pois se tratam de versos alexandrinos, como já explicitamos anteriormente. Além disso, as rimas também são um elemento muito importante para a coesão desse texto, já que são organizadas segundo um esquema que pode ser representado da seguinte maneira:

$$
\text { AA / BBBAA / CCCAA / DDDAA / EEEAA / FFFAA / GGGAA }
$$




\section{Revista do SELL}

v. 6 , no. 3

ISSN: $1983-3873$

As rimas AA representam as rimas do refrão, que já foram descritas como [Car], as rimas $B, C, D, E, F$ e G, presente nas seis estrofes do poema são, respectivamente, as rimas [CeI], [Cews], [Ca], [Cer], [Cor], [Cow]. Como já explicamos anteriormente, o primeiro verso do refrão se repete no último verso de todas as estrofes da cantiga, assim, a rima $A$, presente no refrão, também está presente nas seis estrofes dessa cantiga.

A coerência "torna evidente um sentido que é apreendido globalmente, mesmo que se tenha a impressão de que não há homogeneidade na sua significação" (PORTELA; SCHWARTZMANN, 2012, p. 76), dessa forma, para compreendermos como se dá a construção da coerência em um texto, é necessário que o observemos globalmente, considerando as modalidades da enunciação e as axiologias ou formas de avaliação do discurso. Considerando que a cantiga selecionada busca convencer, através da fé de que a Virgem Maria foi a responsável por dar à luz ao Menino Jesus que, como filho de Deus, desceu à Terra, estamos lidando, então, com um discurso típico de crença, ou seja, uma modalização discursiva que envolve "assumir" e "aderir" e um ato de linguagem persuasivo. Nessa cantiga, fica clara a bondade divina, pois aquele que crê em Deus, não terá nem sede nem fome, como observamos em

(4) Ca Deus en ssi mẽesmo ele mingua non á, nen fame nen sede nen frio nunca ja, nen door nen coyta; pois quen sse doerá del, nen piadade averá nen pesar?

Non deve null' ome desto per ren dultar...

Assim, assume-se a bondade e a grandeza divinas, aderindo-se à crença de que a sua bondade é tamanha a ponto de permitir que o Seu filho encarne através da Virgem Maria para redimir os seres humanos dos seus pecados.

Em relação à intensidade de adesão e à extensão que se buscam por meio do texto na cantiga, fica claro que estamos diante de texto com uma forte intensidade de adesão e com extensão restrita, tratando-se, então, de um texto com valores exclusivos. De acordo com Portela e Schwartzmann (2012, p. 80, grifos dos autores), os valores exclusivos “caminham na direção de valores 'absolutos', que, ao longo de diversos filtros e triagens, vão sendo "purificados", além disso, "os tipos de discurso que empregam tais valores focalizam e valorizam sempre uma temática, uma figura, uma atitude específicas, apurando, refinando, 'descontaminando' os modos”. Desse modo, a cantiga selecionada aponta para um discurso religioso, com a temática do sagrado, enfocando as figuras da Virgem Maria, 


\section{Revista do SELL}

v. 6 , no. 3

ISSN: $1983-3873$

de Deus e de Jesus, com o objetivo de, por meio da descrição das razões pelas quais Deus encarnou Jesus na Virgem Maria, convencer o seu leitor/ouvinte para que acredite na bondade divina e na graça da Virgem Maria e continue temente a Deus e fiel à religião católica.

Concluímos, então, que tanto a coesão textual, que aponta para um texto breve e fechado, quanto a coerência discursiva, que traz o discurso religioso, da fé e do convencimento, convergem para a construção de um texto que busca persuadir o seu leitor/ouvinte por meio da narração do louvor à Virgem Maria e dos motivos que levaram Deus a escolhê-la como progenitora de Jesus. Esse discurso, muito comum na Idade Média, tinha como objetivo manter os indivíduos fiéis ao Catolicismo, seja por meio do convencimento de que somente através da fé poderiam alcançar o Paraíso, seja através do temor das punições divinas. Assim, "o tipo discursivo projeta para fora de sua esfera genérica suas formas enunciativas, seus valores e, até mesmo de maneira mais ampla, uma concepção de mundo e uma forma de um imaginário particulares" (PORTELA; SCHWARTZMANN, 2012, p. 81), o que fica claro na análise da cantiga, em que o discurso religioso remete à concepção de mundo tipicamente monoteísta, em que Deus está acima dos homens por ser seu criador, como observamos em "Onde come a Deus lle devemos amor / e come a Padre e nosso Criador", de modo que os homens devem ter obediência e temor a Deus para que alcancem a vida eterna.

Pensando, enfim, nas CSM como um gênero, constatamos que esses textos possuem características textuais e formais bem delimitadas, tais como a utilização da versificação, das rimas, de versos e estrofes, além da presença de iluminuras, que retratam o que está sendo narrado, e de partituras, utilizadas para a reprodução musical desses textos. Além disso, as CSM também possuem características discursivas particulares, pois o discurso religioso - que busca enaltecer a Virgem e narrar os seus milagres - presente nesses textos, tem como objetivo a manutenção da fé cristã.

\subsection{OBJETO}

Para a semiótica, o nível de pertinência do objeto também diz respeito ao nível dos dispositivos e das técnicas que os operam, dessa forma, tudo que concerne à captação e registro de uma linguagem está relacionado ao nível do objeto, desde o papel e o tipo de 


\section{Revista do SELL}

v. 6 , no. 3

ISSN: $1983-3873$

impressão até às formas de transmissão e captação de uma linguagem qualquer (PORTELA, 2008, p. 104).

Tomando como objeto de análise a cantiga selecionada, Non deve null' ome, observaremos quais os objetos e técnicas que operam para a captação e registro da linguagem presente neste texto. Mas, antes de adentrarmos às nossas discussões, é importante ressaltarmos que todos os textos intitulados Cantiga de Santa Maria possuem características particulares, tais como a presença de iluminuras e de partituras para facilitar a compreensão e a reprodução dessas cantigas. Como não possuímos informações específicas relativas à cantiga selecionada, abordaremos de forma geral esses textos.

Com relação ao texto escrito, as CSM eram produzidas juntamente com a partitura para a reprodução musical, de forma que se mesclam a linguagem escrita, visual e musical. Observando a figura 1, percebemos que os versos da cantiga são inseridos abaixo da partitura, para que os versos possam ser reproduzidos seguindo o compasso da melodia. É interessante observar que, antes do início da partitura, temos o mote da cantiga, que não é acompanhado pela melodia.

Devemos atentar também para o cuidado com que essa partitura é elaborada, o primor da fonte utilizada, dentre outras características, de modo que devemos considerar esses textos não apenas como fonte histórica ou exemplares de textos religiosos, mas também como obras de arte, que carregam traços do cuidado com o registro dessas cantigas. As partituras são muito importantes para o entendimento desses textos, pois, através delas, as cantigas podiam ser reproduzidas por músicos para alcançar um maior número de ouvintes, já que pequena parte da população da época era letrada e a principal forma dessas pessoas terem contato com esses textos era através do canto. A presença da partitura também enfatiza a linguagem poética utilizada nesses textos, pois a utilização da métrica, da versificação e das rimas facilita a reprodução musical desses textos.

\section{Figura 1: Cantiga XV}


v. 6 , no. 3

ISSN: $1983-3873$

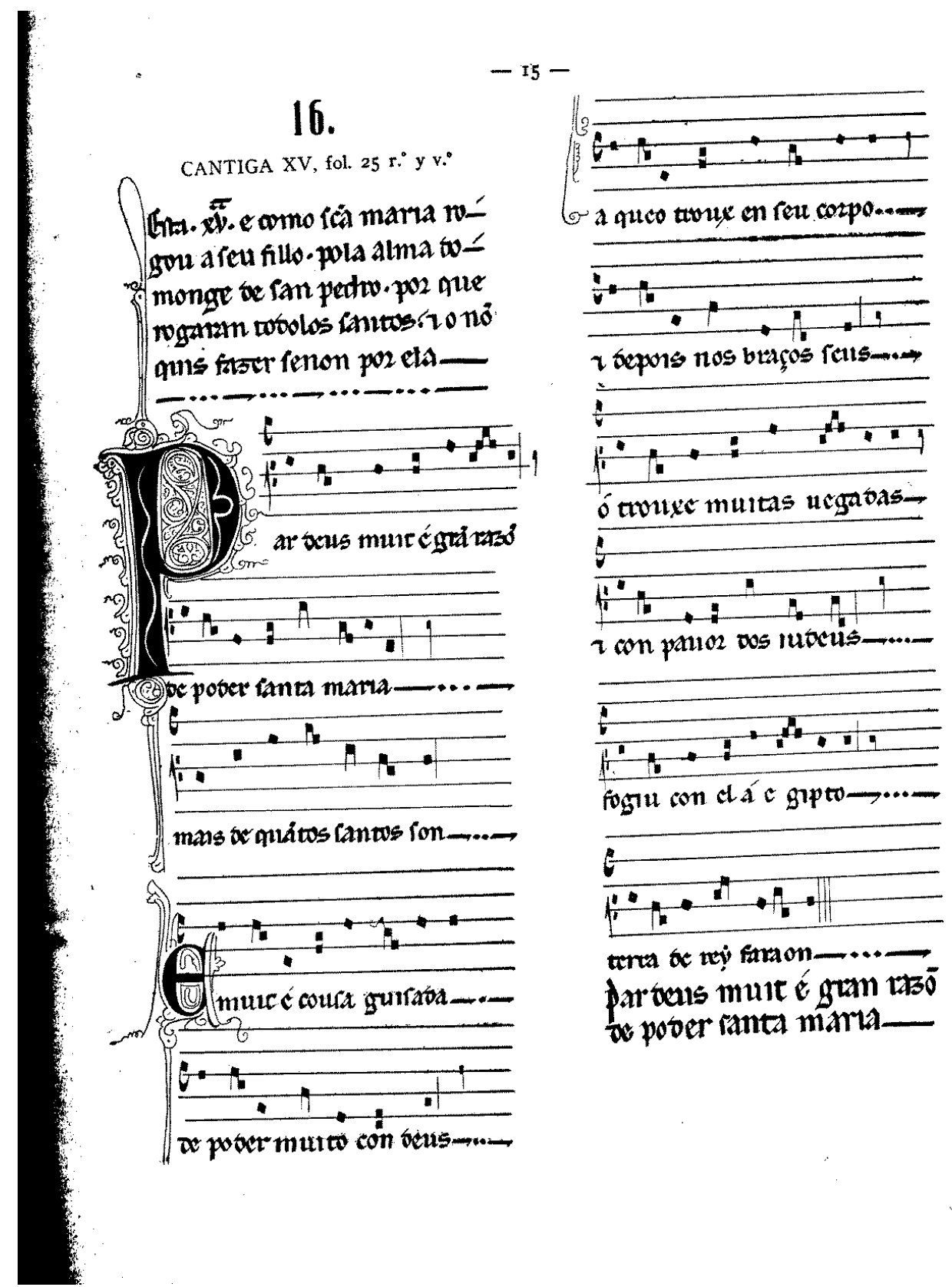

Fonte: http://www.pbm.com/ lindahl/cantigas/facsimiles/To/bob015small.gif (Acesso em 17 ago. 2017)

Figura 2: Ilustração da Cantiga $X$ 


\section{Revista do SELL}

v. 6 , no. 3

ISSN: $1983-3873$

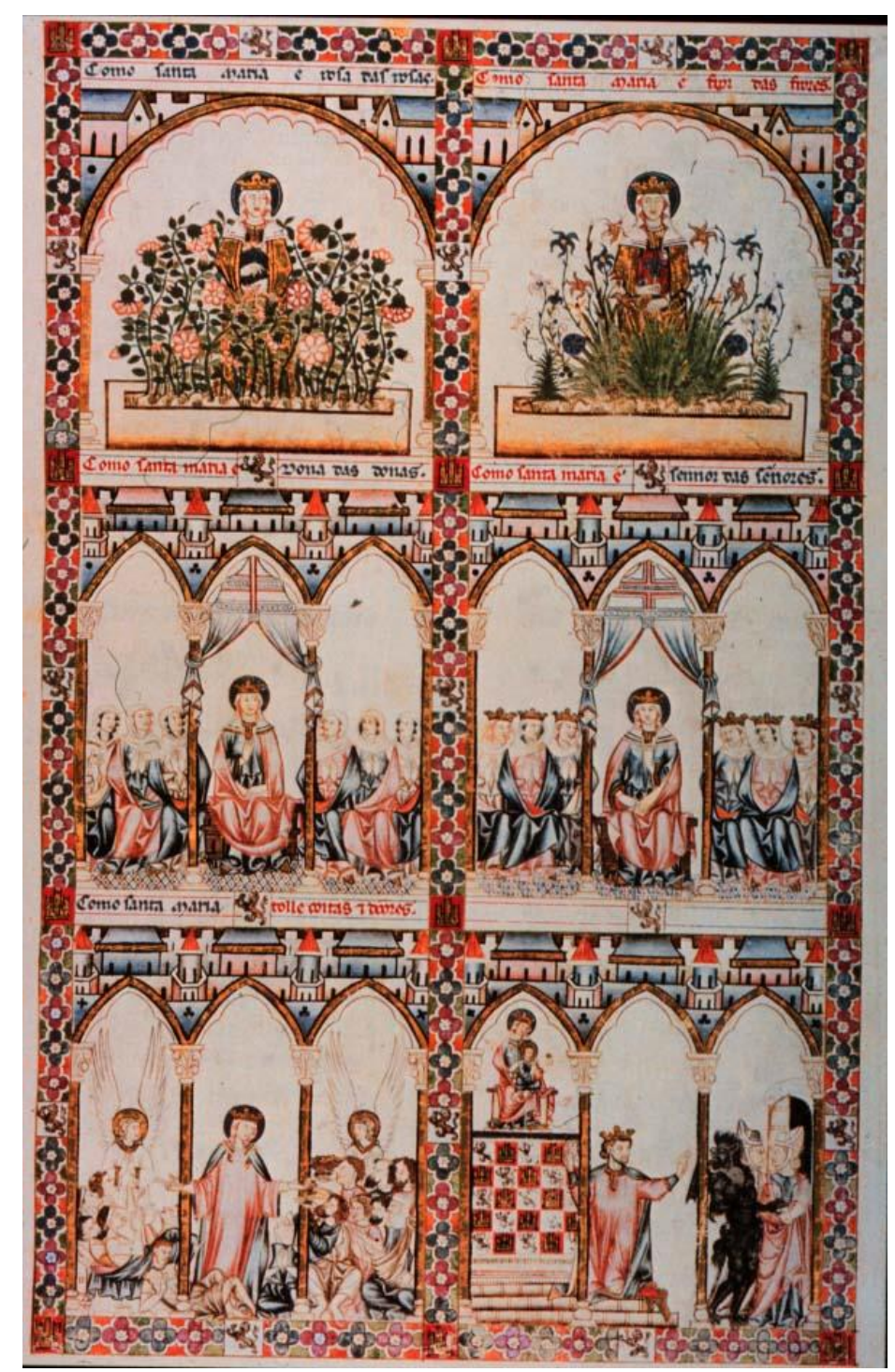

Fonte: http://www.mtholyoke.edu/courses/mtdavis/222/Cantigas10.html (Acesso em 17 ago. 2017)

Por fim, é importante destacarmos as iluminuras presentes nas CSM. A figura 2, que acompanha a Cantiga $\mathrm{X}$, intitulada Rosa das rosas, corrobora a ideia de que as CSM são muito mais do que textos religiosos com intenção de disseminar a fé cristã, mas obras de arte. Ao observarmos essa figura, constatamos a presença da Virgem Maria rodeada por flores nos dois primeiros quadros, de modo que a Virgem é a figura central nesses quadros, com a intenção de destacar a sua beleza, delicadeza, graciosidade, além da sua bondade. Nos quadros seguintes, a Virgem está rodeada por homens e mulheres, além de homens coroados, também disposta de maneira central, levando-nos a interpretar que essa disposição indica que a Virgem é a salvadora e intercessora dos homens comuns e também dos reis. No penúltimo quadro, observamos a Virgem rodeada por figuras angelicais e também por pessoas enfermas que parecem suplicar-lhe por suas vidas. Essa 


\section{Revista do SELL}

v. 6 , no. 3

ISSN: $1983-3873$

representação indica que a Virgem é a intercessora dos homens a Deus, ao mesmo tempo santa e humana. No último quadro, observamos a presença da imagem da Virgem em cima de um altar, além de uma figura da realeza com uma coroa e uma espécie de demônio. Esse último quadro faz-nos compreender que a Virgem é a protetora dos homens, que lhes perdoa os pecados e protege de todo o mal, por isso a escolha do Rei Afonso X em ser seu trovador, como indicam as duas últimas estrofes dessa cantiga:

(5) Devemo-la muit' amar e servir, ca punna de nos guardar de falir; des $i$ dos erros nos faz repentir, que nos fazemos come pecadores. Rosas das rosas e Fror das frores, Dona das donas, Sennor das sennores.

Esta dona que tenno por Sennor e de que quero seer trobador, se eu per ren poss' aver seu amor, dou ao demo os outros amores. Rosas das rosas e Fror das frores, Dona das donas, Sennor das sennores.

Concluímos, então, que na composição das CSM eram utilizadas diversas técnicas para a captação e registro da linguagem textual, através do texto escrito, da linguagem pictórica, através das iluminuras, e da linguagem musical, através das partituras. As várias técnicas utilizadas têm como objetivo principal propiciar a compreensão desses textos, de modo que as iluminuras representam o que está sendo narrado no texto escrito, além de que as partituras possibilitam a reprodução musical desse texto, permitindo que, até mesmo as pessoas não letradas, possam ter acesso a ele. Dessa forma, as diferentes técnicas utilizadas na composição das cantigas tem um mesmo suporte: o papel (ou papiro), no entanto, essas técnicas suscitam diferentes cenas práticas, como veremos adiante.

\subsection{CENAS PRÁTICAS}

Dando continuidade às nossas discussões e analisando a cantiga selecionada do ponto de vista das cenas práticas às quais esses textos pertencem, devemos levar em consideração a proposta de Fontanille (2008, p. 23, grifos do autor) que afirma que as práticas "integram os elementos materiais dos níveis inferiores (signos, textos, objetos) para torná-los distintivos e pertinentes e Ihes dar 'sentido', e de outro lado, recebem um 'sentido' 


\section{Revista do SELL}

v. 6 , no. 3

ISSN: $1983-3873$

de sua própria participação nos níveis superiores (estratégias e formas de vida)". Dessa forma, a cantiga Non deve null' ome está inscrita numa prática de louvar, já que esse texto, quer na sua forma escrita, quer na forma cantada, tem como finalidade louvar à Virgem e trovar sobre as razões pelas quais Deus escolheu-a para dar à luz ao seu filho. Além disso, esse texto também se relaciona a subpráticas, tais como a comoção diante da benevolência divina (nen fame nen sede nen frio nunca ja, / nen door nen coyta; pois quen sse doerá / del, nen piadade averá nen pesar?), a exortação da fé cristã (Nen d' outra maneira non viramos Deus, / nen amor con doo nunca dos feitos seus), o consolo para os pecadores, etc.. Dessa forma, devido às propriedades genéricas e morfológicas da semiótica-objeto Cantiga (versificação, métrica, discurso cristão, etc.), esse texto pode tanto ser lido, como cantado, selecionando a prática de louvor à Virgem.

\subsection{ESTRATÉGIAS}

De acordo com Portela (2008, p. 106) a semiótica "identifica, descreve e analisa as semióticas-objeto, buscando a estratégia enunciativa e enunciva (Greimas; Courtés, 1979) que Ihes permite existir no âmbito da cultura", ainda de acordo com esse autor, "é preciso reconhecer na semiótica uma dimensão estratégica produtiva, que permite que o semioticista não só classifique a existência semiótica, de uma semiótica-objeto, mas diga algo sobre seu devir e seus usos na cultura" (PORTELA, 2008, p. 106). Pensando nas CSM como uma semiótica-objeto e nos seus usos dentro da cultura da época, podemos afirmar que a cantiga selecionada Non deve null' ome, que busca louvar à Virgem, tem como estratégia mostrar a benevolência e o poder divino, e que Deus, por querer fazer-se presente no meio dos homens, mas sem dividir o seu poder, deu ao mundo o seu filho por meio da Virgem Maria, como observamos nas seguintes estrofes:

(6) Ca Deus en ssi mẽesmo ele mingua non á, nen fame nen sede nen frio nunca ja, nen door nen coyta; pois quen sse doerá del, nen piadade averá nen pesar? Non deve null' ome desto per ren dultar...

E poren dos ceos quis en terra decer sen seer partido nen menguar seu poder; e quis ena Virgen por nos carne prender, e leixou-ss' encima, demais, por nos matar. Non deve null' ome desto per ren dultar... 


\section{Revista do SELL}

v. 6 , no. 3

ISSN: $1983-3873$

Dessa maneira, a utilização da estratégia de mostrar a benevolência e o poder divino, ressalta, além da prática de louvar à Virgem, também outras subpráticas de manutenção da fé cristã como já mencionamos anteriormente.

\subsection{FORMAS DE VIDA}

Chegando, então, ao último nível de análise semiótica que abordaremos neste trabalho, é preciso enfatizar que as formas de vida são, de acordo com Portela (2008, p. 107),

o termo resultante (a condensação discursiva) de uma operação complexa de esquematização que parte da materialidade dos enunciados linguísticos, passa pela realização social de seus usos e chega a enunciados mais gerais que os condensam na forma de um jogo codificado de linguagem potencial, característico da práxis enunciativa.

Desse modo, considerando a nossa semiótica-objeto de análise, a cantiga Non deve null' ome, e os outros níveis do percurso gerativo da expressão que já abordamos, podemos afirmar que a forma de vida com a qual estamos lidando é religiosa cristã, predominante na Europa Medieval, na qual as CSM foram produzidas. A forma de vida religiosa cristã envolve a crença de que Deus é onipresente, onisciente e onipotente, além de que os fenômenos da natureza são controlados pela vontade divina - sendo utilizados para punir ou beneficiar a humanidade, de acordo com as suas ações -, e que, de acordo com a vida que levam, os homens podem alcançar a vida eterna, dentre outras crenças. Além disso, essa forma de vida religiosa e cristã envolve também a crença de que Deus escolheu a Virgem Maria para dar à luz ao seu Filho, que morreria para redimir a humanidade dos seus pecados, de maneira que a cantiga analisada louva à Virgem e explicita as razões pelas quais Deus a escolheu. As CSM podem ser consideradas, então, como uma maneira de explicitar essa forma de vida, pois esses textos, tanto de louvor à Virgem, quanto de narração dos seus milagres, propiciam a manutenção da fé cristã.

\section{CONSIDERAÇÕES FINAIS}

Com este trabalho, empenhamo-nos em realizar uma análise semiótica da Cantiga de Santa Maria intitulada non deve null' ome com o intuito de mostrar como o sentido desse 


\section{Revista do SELL}

v. 6 , no. 3

ISSN: $1983-3873$

texto se constrói e como os diversos níveis de análise do percurso gerativo da expressão desde os signos até as formas de vida - colaboram para a composição do sentido nesse texto.

As CSM podem ser consideradas como um gênero textual por apresentarem propriedades formais específicas - tais como a metrificação, versificação, presença de rimas, além da presença de iluminuras, que representam o que está sendo narrado, e partituras, que permitem que esses textos possam ser reproduzidos musicalmente - e discursivas - como o louvor e a narração dos milagres da Virgem Maria, o discurso religioso cristão, a exaltação do poder divino, etc.. Verificamos, então, nas CSM a congruência que define um gênero textual: tanto o tipo textual quanto o tipo discursivo estão em harmonia, o que constatamos ao analisar esse texto em cada nível de pertinência, já que as características textuais dessas obras são fundamentais para a manifestação do discurso religioso presente nessa semiótica-objeto. Portanto, trata-se de um texto congruente, pois circulou numa determinada cultura - Europa Medieval - seguindo as regras de produção e de uso.

Esperamos, com este trabalho, termos contribuído com uma pequena parcela para os estudos semióticos através dessa análise sucinta realizada para compreendermos como o sentido é construído nas CSM, buscando mostrar as principais características formais e discursivas desses textos que são importantes obras para o conhecimento da Língua Portuguesa. 


\section{Revista do SELL}

v. 6 , no. 3

ISSN: $1983-3873$

\section{REFERÊNCIAS}

CORTINA, A.; MARCHEZAN, R. C. Teoria Semiótica: a questão do sentido. In: MUSSALIM, F.; BENTES, A. C. (orgs) Introdução à Linguística: fundamentos epistemológicos. V. 3, 5. ed. São Paulo: Cortez, 2011, p. 393-437.

COSTA, D. S. Estudo do acento lexical no português arcaico por meio das Cantigas de Santa Maria. Dissertação de mestrado FCL-Araraquara/UNESP, Araraquara, 2006.

FIORIN, J. L. Sendas e Veredas da semiótica narrativa e discursiva. DELTA, v. 15, n. 1, 1999.

FONTANILLE, J. Sémiotique et littérature. Essais de méthode. Paris: PUF,1999.

Contexto, 2007.

Semiótica do discurso. Trad. Jean Cristtus Portela. São Paulo:

Práticas semióticas: imanência e pertinência, eficiência e otimização. Tradução de Maria Lúcia Vissotto Paiva Diniz et. al. In: DINIZ, M. L. V. P.; PORTELA, J. C. (Orgs.). Semiótica e mídia: textos, práticas, estratégias. BAURU: UNESP/FAAC, 2008, p. 15-74.

GREIMAS, A. J.; COURTÉS, J. Sémiotique: dictionnaire raisonné de la théorie du langage. Paris: Hachette, 1979.

PORTELA, J. C. Semiótica midiática e níveis de pertinência. In: DINIZ, M. L. V. P.; PORTELA, J. C. (Orgs.) Semiótica e mídia: textos, práticas, estratégias. Bauru: UNESP/FACC, 2008, p. 93-13.

PORTELA, J. C; SCHWARTZMANN, M. N. A noção de gênero em semiótica. In: PORTELA, J. C.; BEIVIDAS, W.; LOPES, I. C.; SCHWARTZMANN, M. N. (Orgs.). Semiótica: Identidades e diálogos. São Paulo: Cultura Acadêmica, 2012, p. 69-98. 


\section{Anexos}

\section{CSM 050 - Non deve null' ome}

Esta é de loor de Santa Maria, que mostra por que razon encarnou nostro sennor en ela.

Non deve null' ome desto per ren dultar que Deus ena Virgen vẽo carne fillar.

E dultar non deve, por quanto vos direi, porque, se non foss' esto, non viramos Rei que corpos e almas nos julgass', eu o sei, como Jeso-Cristo nos verrá joigar.

Non deve null' ome desto per ren dultar...

Nen d' outra maneira non viramos Deus, nen amor con doo nunca dos feitos seus ouveramos, se el non foss', amigos meus, tal que nossos ollos o podessen catar. Non deve null' ome desto per ren dultar...

Ca Deus en ssi mẽesmo ele mingua non á, nen fame nen sede nen frio nunca ja, nen door nen coyta; pois quen sse doerá del, nen piadade averá nen pesar?

Non deve null' ome desto per ren dultar...

E poren dos ceos quis en terra decer sen seer partido nen menguar seu poder; e quis ena Virgen por nos carne prender, e leixou-ss' encima, demais, por nos matar. Non deve null' ome desto per ren dultar...

Onde come a Deus lle devemos amor e come a Padre e nosso Criador, e come a ome del coyta e door avermos de quanto quis por nos endurar. Non deve null' ome desto per ren dultar...

E a Santa Virgen, en que ss' el ensserrou, de que prendeu carne e por madre fillou, muit' amar devemos, ca per ela mostrou todas estas cousas que vos fui ja contar. Non deve null' ome desto per ren dultar... 